THEORIA, 2017, 83, 120-137

doi:10.1111/theo. 12111

\title{
Common Sense and Evidence: Some Neglected Arguments in Favour of $\mathrm{E}=\mathrm{K}$
}

by

\section{ARTUTRS LOGINS}

King's College London and University of Geneva

Abstract: In this article I focus on some unduly neglected common-sense considerations supporting the view that one's evidence is the propositions that one knows. I reply to two recent objections to these considerations.

Keywords: evidence, knowledge, E=K, Peter Unger, John Hyman, reasons

\section{Introduction}

THE AIM OF THIS ARTICLE is to tackle the question of what it is for one to have evidence. ${ }^{1}$ Before addressing the evidence possession question, however, I propose to consider some preliminary remarks.

According to a popular view in contemporary epistemology, how things appear to oneself is all and the only evidence that one has. Roughly, the thought is that one's evidence is in one's head (or at any rate within the borders of one's body) - it is, to use a rather vague but still popular term, constituted by the experience that one undergoes. What exactly experience is, of course, stands in need of further specification. Formulae like "[o]ur experiences - broadly construed - are the only window on the world we have" (cf. Dougherty, 2011, p. 4) and "[e]xperience is our point of interaction with the world - conscious awareness is how we gain whatever evidence we have" (cf. Conee and Feldman, 2008, p. 87) hint at such a specification, for they suggest that experiences are media of some kind: mental entities that represent the world for us in some

1 Notice that this is different from the much-discussed question of the conditions under which something is evidence in favour of a hypothesis (the support question). Despite philosophers' growing interest in the evidence-possession question it is still much less explored than the support question (cf. confirmation theory). 
sense (presumably, this line of thought is inherited from the once-popular sense data theory; cf. Kelly, 2008). ${ }^{2}$

The point of the present article is to defend an alternative picture. In what follows I will put forward the view that our ordinary language use and common-sense judgements about the concept of evidence strongly support the idea that one's evidence consists in all and only propositions that one knows $(\mathrm{E}=\mathrm{K}){ }^{3}$ Peter Unger (in Unger, 1975) and John Hyman (in Hyman, 1999, 2006, 2015) have both proposed considerations in favour of the view that observations about our ordinary language use and common-sense judgements speak in favour of $\mathrm{E}=\mathrm{K}$. Unfortunately, their arguments have often been neglected in contemporary debates about evidence. In this article I will first summarize and explain the considerations of language use and commonsense judgements that Unger and Hyman have proposed in favour of E=K. Second, I will argue against recent objections made against Unger-Hyman-style considerations. In particular, I will argue, contra Hughes (2014), that environmental luck Gettier cases do not pose a problem for Unger-Hyman-style considerations and, contra Littlejohn (2012), that cases of stubborn belief in the presence of misleading evidence can be accommodated by a proponent of Unger-Hyman-style considerations.

I acknowledge that $\mathrm{E}=\mathrm{K}$ might still be false, despite the fact that common sense suggests that $\mathrm{E}=\mathrm{K}$ is true and there are no correct considerations about common sense that speak in favour of alternative views of evidence possession. Yet I also think that discrediting considerations about language use and commonsensical judgements merely because of the possibility of being misled by them seems to be excessively pessimistic. Moreover, it seems that there are also more theory-driven arguments in favour of $\mathrm{E}=\mathrm{K}$ that allow preferring it to its alternatives: arguments based on the theoretical utility of a conception of evidence. ${ }^{4}$ I limit myself here only to mentioning that such theory-driven arguments in favour of $\mathrm{E}=\mathrm{K}$ have been

2 One popular way of making the appeal to "experiences" more specific is to introduce the phenomenal conception of evidence. The term "phenomenal conception of evidence" was coined by Timothy Williamson (2000, pp. 173-174); see also Kelly $(2008$, 2014). Other labels for (roughly) the same view include "evidential internalism" (Silins, 2005) and "internalist mentalism" (cf. Conee and Feldman, 2004, p. 55). The phenomenal conception of evidence states: necessarily, if two subjects, S1 and S2, are internally alike, then S1 and S2 are equally alike with respect to what evidence they possess (see BonJour, 1999; Audi, 2001; Wedgwood, 2002; Conee and Feldman, 2004, 2008, 2011; and Silins, 2005). For two subjects to be internally alike is for them to be in relevantly similar (same in some sense) non-factive mental states. Paradigmatic non-factive mental states include beliefs, seemings, apparent experiences, appearings, feelings, imaginings, etc. These states have in common that they do not require the truth of their content (see Wedgwood, 2002). The main line of argument that proponents of the phenomenal conception of evidence typically offer in its favour is its alleged plausibility in the light of our pre-theoretical intuitions and common-sense judgements. Compare, for instance, Conee and Feldman (2008, p. 87).

3 E=K has been defended by Unger (1975, pp. 206-211), Hyman $(1999,2001)$ and Williamson (2000, pp. 184-237).

4 Thanks to Robin McKenna for pressing me on this point. 
notably presented by Timothy Williamson (2000; see in particular Chapters 9 (on evidence) and 10 (on evidential probability)). In what follows I will not pursue a discussion of these arguments. Rather, I will only focus on the often overlooked claim that some considerations about ordinary language use and common-sense judgements strongly support the $\mathrm{E}=\mathrm{K}$ view.

The $\mathrm{E}=\mathrm{K}$ thesis is composed of two sub-theses: $\mathrm{E} \rightarrow \mathrm{K}$ (that all evidence is knowledge) and $\mathrm{K} \rightarrow \mathrm{E}$ (that all knowledge is evidence). The present article will be specifically concerned with $\mathrm{E} \rightarrow \mathrm{K}$. In a sense the debate about $\mathrm{E} \rightarrow \mathrm{K}$ is the key debate for a proponent of $\mathrm{E}=\mathrm{K}$, for it is the most contentious part of the $\mathrm{E}=\mathrm{K}$ equation. It is also the part of $\mathrm{E}=\mathrm{K}$ that has been most discussed in the literature. In particular, most positive arguments for $\mathrm{E}=\mathrm{K}$ have been arguments for $\mathrm{E} \rightarrow \mathrm{K}$, and most of the arguments allegedly undermining $\mathrm{E}=\mathrm{K}$ have been those targeting $\mathrm{E} \rightarrow \mathrm{K} .{ }^{5}$ This asymmetry is respected here. With these remarks in mind we can now turn to the Unger-Hyman-style arguments in favour of $\mathrm{E} \rightarrow \mathrm{K}$.

\section{Unger's (and Hyman's) Arguments for $\mathbf{E} \rightarrow \mathrm{K}$}

One of the first, if not the first, contemporary epistemologist to seriously consider the view that if a proposition is part of one's evidence then one knows it (i.e., the $\mathrm{E} \rightarrow \mathrm{K}$ claim) was Peter Unger. More specifically, Unger defends the following claim $(\mathrm{R} \rightarrow \mathrm{K})$ :

If S's reason (for something $\mathrm{X}$ ) is that $p$, then $\mathrm{S}$ knows that $p$, and if $\mathrm{S}$ 's reasons (for $\mathrm{X}$ ) are that $p$ and that $q$ and so on, then S knows that $p$ and S knows that $q$ and so on. (Unger, 1975, p. 206) ${ }^{6}$

5 A non-exhaustive list of opponents to $\mathrm{E}=\mathrm{K}$ (or the associated view about reasons for belief) includes: Arnold (2013), Brueckner (2005), Comesaña and Kantin (2010), Conee and Feldman (2008), Dodd (2007), Dougherty and Rysiew (2013), Dunn (2014), Goldman (2009), Harman (2002), Hawthorne (2005), Hughes (2014), Ichikawa (2013), Jackson (2012), Joyce (2004), Kelly (2008), Littlejohn (2011a, 2011b, 2012), Logins (2013), McGlynn (2014), Mitova (2015), Neta (2008), Rizzieri (2011), Schiffer (2009), Schroeder (2011), Silins (2005), Turri (2009) and Whitcomb (2008). As far as I can see only the objections from Brueckner (2005), Conee and Feldman (2008), Goldman (2009), Hughes (2014), Joyce (2004), Littlejohn (2011b, 2012) and McGlynn (2014) have (at least partly) focused on arguments that have been proposed in favour of $\mathrm{E}=\mathrm{K}$, instead of merely pointing to some allegedly implausible consequences of $\mathrm{E}=\mathrm{K}$.

6 Although Unger's claim, as stated, is about one's reason or reasons for X, it is natural to assume that Unger is committed to the claim that evidence entails knowledge. Unger states explicitly that one's reasons to believe have to be known, that is, according to Unger, $\mathrm{X}$ in "reason for X" can be belief (cf. Unger, 1975, pp. 198, 209). Evidence is at least one sort of reason for believing that one can have. According to a widely shared view, something even stronger holds: only evidence can be one's reason to believe. Unger endorses the view that only one's evidence can be "normal sort of reason" for one to believe (cf. Unger, 1975, p. 38). We have good reasons for thinking that if $\mathrm{R} \rightarrow \mathrm{K}$ holds then $\mathrm{E} \rightarrow \mathrm{K}$ holds. Any argument for the former can also be taken as an argument for the latter. Indeed, it would be rather odd to claim that evidence is never even a subset of one's reasons to believe something. At any rate, Unger is committed to the view that every argument for $\mathrm{R} \rightarrow \mathrm{K}$ will be an argument for $\mathrm{E} \rightarrow \mathrm{K}$. Hence, in what follows I will use " $\mathrm{R} \rightarrow \mathrm{K}$ " and " $\mathrm{E} \rightarrow \mathrm{K}$ " interchangeably. 
This claim constitutes a premise in Unger's argument for scepticism about rationality. Unger endorses scepticism about knowledge (e.g., that nobody knows anything), and argues in favour of the (linking) claim that "[i]f it is true that nobody ever knows anything to be so, then it follows that it is also true that nobody is ever (even the least bit) reasonable or justified in anything, in particular, in believing anything to be so" (Unger, 1975, p. 198). These two claims then entail scepticism about rationality/reasonability. The claim in which we are interested (i.e., the above quotation) constitutes a premise in Unger's so-called "Basis Argument" (it concerns the bases or grounds for acting and believing that are constituted by known propositions, cf. (Unger, 1975, pp. 200-201) for the linking claim (the sceptical linking)). ${ }^{7}$

In this section I propose to focus mainly on Unger's language use and commonsense argument for $\mathrm{R} \rightarrow \mathrm{K}$. Nonetheless, Unger is not the only one to propose this kind of consideration in favour of $\mathrm{R} \rightarrow \mathrm{K}$. John Hyman has equally proposed similar views on various occasions (cf. Hyman, 1999, 2001, 2006, 2015). Indeed, many of the crucial parts of their respective arguments seem to be the same. In particular, the claims that common sense dictates that not only does one have to truly believe a proposition in order to have it as a reason for $\mathrm{X}$, one has also to know it (e.g., Gettier cases, and other cases of justified true beliefs cannot constitute one's reasons for X). Hence, in order to keep the discussion as focused (on arguments) as possible I will abstain from offering a detailed exegesis of Hyman's approach, mainly presenting the first appearance of this style of argument in Unger (1975). I say "mainly", since, at some points in the present article, I will appeal to additional insights from Hyman that cannot be found in Unger's text.

Unger's argument for the claim that if S's reason for $\mathrm{X}$ is that $p$, then $\mathrm{S}$ knows that $p,{ }^{8}$ consists of two steps. First, on the basis of linguistic observations Unger concludes that when $p$ is $\mathrm{S}$ 's reason for $\mathrm{X}$, then $\mathrm{S}$ satisfies all necessary conditions for knowing $p$. Second, Unger claims that nothing short of knowledge is sufficient for $p$ to be S's reason for X. Namely, even if most of the conditions for knowledge are satisfied, but the subject does not know (that $p$ ), then it cannot be said (felicitously) that the subject has it (i.e., that $p$ ) as a reason. Hence, only knowledge can constitute one's reason for X. This division of Unger's argument into two steps should not be taken too strictly. The first step does not consist in establishing a lemma, which is then assumed in the next step of the argument. Rather, the first step is better considered as removing obstacles to accepting the

7 Needless to say, the defence of one of Unger's premises does not commit us to his sceptical conclusions.

8 For the sake of brevity, I will put Unger's claim in the singular as a claim about a subject's reason and not always mention the plural version of it (the claim about a subject's reasons). 
claim that having reasons entails knowing, while the second step can be considered as providing some more specific considerations in favour of that claim. In the remainder of this section I will present in a little more detail both steps of the argument. One might think, however, that since strictly speaking only the second step can potentially support the specific $\mathrm{R} \rightarrow \mathrm{K}$ claim, we should skip the first and focus our attention on the second. After all, we are after a defence of the specific claim that (one's) reasons entail knowledge. ${ }^{9}$ To this I would like to reply that a brief presentation of the first step can, nonetheless, be dialectically beneficial. This is so not only because the first step prepares the ground for the more specific considerations (by narrowing down the options for a theory of evidence possession), but also because if after all the second step were rejected by my opponents, the first step considerations alone would already be enough to undermine the claim that common sense favours the most popular rival approach to evidence, the phenomenal conception of evidence (see n. 2). For the phenomenal conception of evidence appears to be incompatible with the factive conception of evidence (i.e., a view according to which only true propositions (or, alternatively, facts, if the two are not the same) can constitute one's evidence). Thus, I believe, we should not skip the first step of Unger's argument.

The first step of Unger's positive argument consists in maintaining that linguistic considerations favour the view that having a reason $p$ entails what he takes to be necessary conditions for knowing $p$. Namely, Unger claims that (true) locutions of the type "S's reason is that $p$ " entail that $p$, that $\mathrm{S}$ believes that $p$, and that $\mathrm{S}$ is absolutely certain that $p$. Unger thinks that these considerations from our language use constitute good evidence for the claim that someone's reason entails their knowing. In order to make his claim Unger submits that the following locutions are inconsistent (Unger, 1975, pp. 208-209):

1. His reason was that the store was going to close, but it wasn't going to close.

2. His reason was that Fred's hat was wet, but he didn't even believe that it was.

3. Ralph's reason was that Fred's hat was wet, but he wasn't absolutely certain that it was.

Locutions of the first form (1) indicate that reason entails truth. For if it were not the case that reason entailed truth, then (1) would be consistent. It does not sound felicitous (and there seems to be no good alternative explanation of this fact), which indicates that it is inconsistent and hence we can infer that reason entails truth.

9 I would like to thank an anonymous referee for pressing me on this. 
Unger's focus is on personal reasons. ${ }^{10}$ Yet, in order to make his point about the factivity of personal reasons, he also appeals to our intuitive judgements about explanatory reasons. According to Unger, the locution "the reason is that it was going to close, but it wasn ' $t$ ', which concerns an explanatory reason, seems clearly infelicitous. Unger suggests that it seems as infelicitous as locution (1), which concerns a personal reason. Hence, Unger concludes, the factivity of reason (i.e., that reason entails truth) is a common feature of both explanatory and personal reasons. ${ }^{11,12}$

10 Unger distinguishes between " $S$ 's reason for $X$ " and "the reason that S X-es" (Unger, 1975, p. 207). In short, the former is a personal or guiding reason for doing or believing something; the latter is an explanatory reason for why someone does what she does. Unger notices that, contrary to how it may seem, in many situations there are only explanatory reasons. There can be an (explanatory) reason why someone eats sweets, namely because her body needs sugar. However, it may well be the case that this is not her reason for eating sweets; it can even be the case that she eats sweets for no (personal) reason. Unger's thesis is concerned with personal reasons. Here is one potential difference with Hyman's argument. Hyman thinks that there are explanatory reasons: reasons why one believes (or F-s in general). Explanatory reasons are factive. In normal cases, according to Hyman, the reason why one believes that $\mathrm{p}$ is also one's reason for believing (the ground on which one believes, a personal reason). Since reasons why are factive, one's reasons for believing in normal cases are facts. Hence, Hyman's defence of $\mathrm{R} \rightarrow$ $\mathrm{K}$ may be seen as a defence of a more nuanced claim that when one's reason for believing (one's ground for believing) is a fact, one knows that fact. See Hyman (1999, p. 446; 2015, pp. 133-158).

11 We can find additional considerations in favour of factivity in Hyman's writings. As we have already observed, Hyman notices that explanations are factive. Hence, explanations which provide one's reasons for doing something or believing a proposition are factive. According to Hyman: “ $A \Phi$ ed because $p$ ' implies that $p$, and so does ' $B$ believes that $q$ because $p$ "' (cf. Hyman, 1999, p. 443). The thought is that sometimes we provide explanations of action or belief that appeal to one's reasons for that action or belief. Hyman notices that we often explain action and belief by appeal to "mental states or dispositions, or requests or goals" (cf. Hyman, 1999, p. 443). Crucially, however, when we provide the reason for which one does or believes something in our explanation of action or belief, we are providing facts, for explanations are factive. See also Hyman (1999, p. 445) for a line of argument against the possibility of false reasons.

12 The factivity of (personal) reasons for believing is accepted by everyone. Notably, Jonathan Dancy has proposed considerations about intuitive judgements that he takes to undermine the factivity of reasons. One such consideration seems to appeal to the putative felicity of (a): "His reason for doing it was that it would increase his pension, but he was sadly mistaken about that" (Dancy, 2004, p. 26). However, it is not clear that Dancy's objection gets off the ground. One potential problem with it is that it is not clear what exactly our intuitions are about in this case. For instance, one may claim that (a) appears acceptable because "mistaken about that" in the consequent refers to the agent's doing it (whatever it is) and not to "it would increase his pension"; in which case, we might think of (a) as a sort of evaluative judgement of the appropriateness of the subject's action. If, however, "mistaken" refers to subject's belief rather than action, then it is questionable whether the literal version of (a) is acceptable after all. One may think that (a) appears acceptable only because it is taken to imply (a'): "His reason for doing it was that he believed that it would increase his pension, but he was sadly mistaken about that", which does not entail that the reason was false. Quite the contrary, (a') implies that the subject's reason was that she believed a proposition. Of course, only the alleged felicity of the literal sense of (a) may raise a worry for the factivity of reasons. See Hyman (2015, pp. 146-149) for another line of reply to Dancy's views. See also Hornsby (2007, 2008). Arnold (2013), Comesaña and Kantin (2010), Fantl and McGrath (2009), Goldman (2009), Joyce (2004) and Rizzieri (2011) constitute further recent defences of the possibility of false evidence. More defences of the factivity of evidence can be found in Leite (2013), Littlejohn (2012) and Mitova (2015). Thanks to a referee here. 
Locutions like (2) are intended to show that reason also entails belief. For if reason did not entail belief (and unless there is an alternative plausible explanation of our linguistic intuitions), then it should be perfectly felicitous to utter (2) and the like. However, it is not felicitous to utter (2) and there seem to be no alternative plausible explanation for this. Hence, (2) is inconsistent and indicates that reason entails belief. ${ }^{13}$

Unger also thinks that having a reason entails a condition that is not normally entailed by anything less than knowledge. This condition, according to Unger, is being absolutely certain that $p .{ }^{14}$ The alleged infelicity of locution (3) is intended to show that having a reason entails being absolutely certain. Hence, Unger takes it that the fact that truth, belief and being absolutely certain are entailed by having a reason and also by knowing constitutes good evidence for the view that having a reason entails knowledge. ${ }^{15}$

The second step of Unger's argument is to claim that there is good evidence for the view that one has to know $p$ in order for $p$ to be one's reason. Unger thinks that if the subject does not know that $p$, then $p$ is not the subject's reason. Consider the following case that Unger offers in support of this conclusion:

Suppose, then, that Mary believes that the crops will grow now and she says that her reason for believing it is that it was raining. But Mary does not know that it was raining, even though she meets many necessary conditions of knowing it ...

In this situation, it is true that it was raining. And, Mary is perfectly certain that it was. Moreover, Mary's certainty is based on grounds which are quite good. But here is how all of this happened. Mary was indoors but then she came outside and looked around. The ground and objects outside were all wet just as if wetted recently by falling rain. And, other indications all pointed to its having rained. Indeed, this is why Mary is certain that it was raining. But, unbeknownst to Mary, while it did in fact rain, the rain was rapidly evaporated due to some extraordinary events: For one, the temperature outside went up to $130 \mathrm{~F}$. for an hour. Right after the evaporation, some huge spray-and-sprinkle trucks swept by and covered the area with water

13 Note also that this consideration provides at least some grounds for preferring $\mathrm{E}=\mathrm{K}$ to alternative factive views of evidence possession that do not require belief condition but only the condition of being in a position to believe. Presumably, such views might have difficulties in accounting for this part of Unger's data. Thanks to an anonymous referee for drawing my attention to this issue.

14 "That someone be absolutely certain is something which is entailed by little which does not also entail knowing. But it is entailed by someone's reason" (Unger, 1975, p. 209).

15 Unger's appeal to considerations about (3) and the like are problematic in at least two aspects, though. For one thing, it is not clear (at least not as straightforwardly as with (1) and (2)) that (3) does sound infelicitous. Furthermore, if we understand "being absolutely certain" in terms of psychological certainty (as contrasted to objective certainty), as Unger seems to do (cf. Unger, 1975, p. 105), then it is not clear at all that the claim that certainty is "entailed by little which does not also entail knowing" is plausible at all, for there are many ways in which one could be in such a psychological state without it also entailing knowledge. We could make pills that make people absolutely confident, for instance. Thanks to Julien Dutant and Robin McKenna here. 
again, and they did it in just the way that rain does. So, it all looked just as if nothing had evaporated. Because she sees the water, Mary is certain that it was raining. And, because she is certain of this, Mary thinks that the crops will grow now. Now, it is of course true that it was raining. But is it true that Mary's reason for thinking this about the crops is that it was raining? (Unger, 1975, pp. 209-210)

Unger's verdict on this case (which in fact corresponds to typical Gettier situations - a situation in which a subject's true belief fails to be knowledge, while being at the same time justified in some specific sense) is that the fact that it was raining is not Mary's reason. ${ }^{16}$ Moreover, Unger suggests that perhaps there is nothing that is Mary's reason. That is not to say that there is no (explanatory) reason why Mary thinks that the crops will grow now, of course. The distinction, which Unger makes in his preliminary remarks and which I have called the distinction between personal and explanatory reasons, makes it clear that there can be cases where there is a reason why someone does something without there being a personal reason for which the subject does it. This general distinction applies to Mary's belief. ${ }^{17}$

Notice also that there is no special difficulty for someone who endorses Unger's line of thought to explain why Mary says that her reason for believing that the crops will grow now is that it was raining. The explanation consists in appealing to the fact that Mary thinks that she knows that it was raining. Mary says that her reason is that it was raining, because she thinks that she knows that it was raining. ${ }^{18}$

16 A more general observation, not dealing with Gettier cases in particular, is given in Unger (1980), where he provides linguistic considerations in favour of the view that reasons entail knowledge: "The most direct evidence comes with inconsistent sentences like 'His reason (for believing it) was that there were footprints there, but he didn't know that there were.' Related sentences conspire to confirm: 'His evidence was that there were, but he didn't know that there were.' And the more widely we look to examine the phenomena, the more broadly based our confirmation becomes" (Unger, 1980, p. 532). The sentence "His reason (for believing it) was that there were footprints there, but he didn't know that there were" sounds a bit odd to my ears.

17 Hyman's considerations contain some additional details. Hyman notices that what is too chancy cannot be one's reason for doing or believing something. This seems to be a central intuition underlying some of his own cases (e.g., the betting case in Hyman, 1999, p. 447, and the truffles case in Hyman, 1999, pp. 446-447). True beliefs can be chancy, as is especially well evidenced by the betting example. Mere true beliefs can easily be false. Hence, mere true beliefs cannot be one's reasons for doing or believing something. This seems to support $\mathrm{R} \rightarrow \mathrm{K}$ in a rather more theory-driven sense. Hyman has also proposed considerations against the view that a mere justified true belief (that does not amount to knowledge) is enough for having a reason for X (cf. Hyman, 1999, pp. 447-448). In particular, Hyman suggests that our intuitions about Gettier cases constitute evidence for the view that only known propositions are reasons/evidence.

18 Thanks to Tim Williamson here. 


\section{3. $\mathbf{E} \rightarrow \mathrm{K}$ and Environmental Luck Gettier Cases}

Recently (after decades of apparent neglect) epistemologists have begun to seriously address Unger and Hyman's defence of $\mathrm{R} \rightarrow \mathrm{K}$. In particular, two notable objections have been recently proposed by Nick Hughes (2014) and Clayton Littlejohn (2012). I believe, however, that their objections ultimately do not manage to undermine the Unger-Hyman line of defence of $\mathrm{R} \rightarrow \mathrm{K}$. In this section I sum up and reply to Hughes's objection and in the next section I sum up and reply to Littlejohn's considerations.

Hughes argues that our intuitions about some possible cases suggest that $\mathrm{R} \rightarrow \mathrm{K}$ does not hold. ${ }^{19}$ We can think of his argument in the following way. In some cases it is intuitive to conclude that $p$ is a subject's reason for F-ing ${ }^{20}$ while at the same time $\mathrm{S}$ does not know that $p$. If our only arguments for $\mathrm{R} \rightarrow \mathrm{K}$ are based on intuitions, then even if we were to accept Unger-Hyman considerations, we should nevertheless suspend judgement about $\mathrm{R} \rightarrow \mathrm{K}$, since we do not have a principled way to exclude Hughes's intuitions. Now, the crucial point of Hughes's argument, of course, is the claim that some intuitions suggest that $\mathrm{R} \rightarrow \mathrm{K}$ does not hold. This claim concerns Gettier cases of the so-called fake barn variety (cf. Goldman, 1976). ${ }^{21}$ Here is how Hughes presents the fake barn Gettier case:

Henry is driving through the countryside looking at objects off the road. He sees what looks to him exactly like a barn. In fact it is a barn, but unbeknownst to Henry, he is in 'fake barns' country - an area with only a few real barns and many barn facades designed to look exactly like real barns to passing motorists. Luckily for Henry, he happens to look at one of the only real barns in the area. Henry's belief is justified and true, but not an item of knowledge. (Hughes, 2014, p. 459)

By slightly adapting the cases and overall considerations proposed by Hughes, we can sum up his line of thought as follows. Henry believes that there is a barn. Intuitively, that there is a barn is Henry's reason for some F-ing, say, for stopping and taking a picture of a barn, or for believing that he saw a barn. Given that Henry does not know that there is a barn, this is a case where $p$ is one's reason for F-ing but one does not know that $p$. Hence, overall considerations about intuitions suggest that "we should be reluctant to accept [R $\rightarrow$ K]" (cf. Hughes, 2014, p. 461).

19 See also Brown (2008, p. 172) for a similar intuition.

20 Hughes considers the more general claim about one's reasons for F-ing, not merely the claim about one's reasons for believing.

21 Hughes calls them "causal Gettier cases", since the fact that $\mathrm{p}$ is causally related to the subject's (justified true) belief. These are contrasted to Gettier cases where there is no causal relation between the fact that $\mathrm{p}$ and the subject's belief (cf. Hughes, 2014, p. 459). Hughes also notes that causal Gettier cases will be in large part cases of "environmental luck Gettier cases" (cf. Pritchard, 2008), where the subject's achievement of having a true justified belief is a result of her cognitive abilities. Environmental luck Gettier cases are distinguished from intervening luck Gettier cases. 
In reply to Hughes I would like to make two observations and draw some conclusions from them. First, it has to be noted that we have some grounds for questioning the claim that the fact that $p$ is one's reason for F-ing in the fake barn Gettier case is an intuitive judgement about such cases. For instance, according to Hyman the intuitive judgement in such cases is that that $p$ cannot be one's reason for F-ing. Hyman has put forward this kind of judgement in a recent publication (Hyman, 2015). Here is the version of a fake barn scenario that Hyman proposes there:

George is touring the countryside in upstate New York. Delighted by the picturesque barns dotting the landscape, he photographs them one by one. Unbeknownst to him, most in fact consist only of façades, which the local tourist authority has arranged to look like barns from the road, but by chance one of the photographs he takes is of a real barn. (Hyman, 2015, p. 156)

With respect to this case Hyman then states:

[W] hatever the right explanation is, it seems clear that George does not know that he is photographing a real barn, and equally clear that he does not take the photograph because the structure is a barn, even though he can be expected to give this reason, should he be asked. (Hyman, 2015, pp. 156-157, original emphasis)

He then suggests what might be one's reason for F-ing in this case. ${ }^{22}$

Presumably, the reason why he takes this photograph is the same as the reason why he takes the others, namely, that he believes it is a barn, or that it looks like one. (Hyman, 2015, p. 157)

I have no valid reason for doubting the sincerity of Hyman's judgement. It hardly seems deniable that he has the intuition that George's reason for taking the photograph is not that it is a barn. Hyman does not share Hughes's intuition that in a fake barn case that $p$, something that one does not know despite believing it truly and justifiably, can be one's reason for F-ing. On the contrary, he has the intuition that in such cases $p$ cannot be one's reason for F-ing.

Now, what can we make of this disagreement about intuitions? In short, I believe, we should take it seriously while limiting its impact. I think that first of all we should take seriously the distinction between typical Gettier cases and fake barn Gettier cases. There are good reasons for taking this distinction seriously: the structural difference is a substantial one (as illustrated by the environmentalinstrumental Gettier case taxonomy). The important thing then is that our intuitions about the absence/presence of a personal reason for F-ing in the typical Gettier cases and in the fake barn case should not be put on a par. The structural difference between these cases provides us with a theoretical motivation for such

22 Note that Hyman's term "the reason why one F-s" corresponds (roughly) to what we call in this article one's reasons for F-ing. Hyman appeals here to the "reason why one F-s" as used in "standard because-explanations" (cf. Hyman, 2015, p. 133ff). 
a distinction. Now, we can observe that everyone (e.g., Hyman and Hughes alike) agree that there is no reason (in the relevant sense) in the typical Gettier cases. The divergence concerns only the fake barn cases. One way of assessing radically divergent intuitions is to consider them noise in the data. In short, contrary intuitions may warrant suspension of judgement about the matter (absent other studies or theoretical reasons, of course). Hence, one not far-fetched way of drawing a conclusion from the clash of Hughes's and Hyman's intuitions (while awaiting further studies) is to suspend judgement about whether the subject has a reason for F-ing in the fake barn case. However, this does not entail that we are warranted in suspending our judgement about the presence/absence of reasons in typical Gettier cases. After all, Hyman and Hughes both agree that it is intuitive to think that there is no reason in the typical Gettier cases (in the relevant sense). Scepticism about the relevance of the intuitions about reasons in the fake barn case should not move us towards scepticism about the intuitions about reasons in typical Gettier cases. If this is right, then considerations about the presence/ absence of personal reasons for F-ing in typical Gettier cases still support the $\mathrm{R} \rightarrow \mathrm{K}$ claim, while considerations about the presence/absence of reasons in the fake barn case may be reasonably taken to be irrelevant since on balance they neither support nor undermine the $\mathrm{R} \rightarrow \mathrm{K}$ claim.

Second, and related to the first, while Hughes is right that only a minority in contemporary epistemology defend the view that one can know in the fake barn scenario, there is growing consensus in epistemology that our intuitions about the fake barn cases are not straightforward. In particular, it has been argued that our intuitions about knowledge attribution in the fake barn case are susceptible to radical variations depending on the framing of the case (cf. Gendler and Hawthorne, 2005). A number of recent empirical studies on intuitions about Gettier cases seem to suggest similar conclusions (cf. Colaco et al., 2014; Turri et al., 2015, and further references therein). I think we can draw two important points from this. First, the fact that intuitions vary about knowledge in the fake barn case adds further reason for not taking reports of intuitions about the presence/absence of reasons for F-ing in the fake barn case too seriously. Second, the fact that we have varying intuitions about knowledge in the fake barn case, of course, does not undermine our judgements about Gettier cases in general. We still think that there is a good case against the justified true belief account of knowledge, given typical Gettier cases. That is, even if we were to admit that we cannot draw many conclusions from our intuitions alone in fake barn cases, we will not, of course, say that intuitions do not support the view that justified true belief is insufficient for knowledge. Now, in parallel, it seems equally reasonable to think that the fact that we sometimes find it intuitive to think that one has a reason in the fake barn case does not undermine the claim that intuitions, on balance, support the idea 
that if one does not know that $p$, then $p$ cannot be one's reason for F-ing. Intuitions about fake barn cases vary a lot depending on framing. They clearly vary about knowledge attribution in such cases, and presumably they also vary about reasons for F-ing attribution. This seems to be good enough ground for not taking intuitions about fake barns too seriously in theorizing about reasons. These intuitions are more akin to noise in data than to data that we can use in our theoretical considerations. Hence, I suggest that Hughes's appeal to intuitions about the presence of one's reasons for F-ing in the fake barn case does not undermine UngerHyman positive considerations in favour of $\mathrm{R} \rightarrow \mathrm{K}$.

\section{4. $\mathrm{E} \rightarrow \mathrm{K}$ and Cases of Stubborn Belief and Misleading Evidence}

Clayton Littlejohn has proposed in his 2012 book a detailed examination and critique of Unger's linguistic argument for $\mathrm{E} \rightarrow \mathrm{K}$. After considering an objection to Unger's linguistic considerations, he accepts that Unger's linguistic evidence does provide some support for $\mathrm{R} \rightarrow \mathrm{K}$ (Littlejohn, 2012, pp. 102-103). However, he does not endorse $\mathrm{R} \rightarrow \mathrm{K}$ there. ${ }^{23}$ He suggests there that $\mathrm{R} \rightarrow \mathrm{K}$ has implausible consequences. He states:

I am not entirely convinced that Known Reasons [i.e., 'If $p$ is your reason for $\Phi$-ing, you know p.' (Littlejohn, 2012, p. 102)] is correct. Known Reasons predicts that this could be a successful challenge to [the claim (CLAIM) that Audrey's reason for going to the store was that she was out of coffee (Littlejohn, 2012, p. 102)]:

IC.

Audrey believed that she was out of coffee, but her belief was not justified. There was a ton of misleading evidence that was planted in the hopes of tricking her into thinking that she had coffee. She knew of the evidence, but she completely ignored it. So, her reason for going wasn't that she was out of coffee.

The considerations offered might show that Audrey's belief was not justifiably held and did not satisfy the conditions necessary for knowledge, but they do not threaten [(CLAIM)]. (Littlejohn, 2012, pp. 103-104)

Here is how I understand Littlejohn's objection. If $\mathrm{R} \rightarrow \mathrm{K}$ were true, then (IC) would be a good argument that (CLAIM) is false. However, we do not feel that (IC) is a good argument that (CLAIM) is false. In particular, in the situation (IC) where Audrey is out of coffee, she believes that she is out of coffee, she has

23 In more recent writings Littlejohn has changed his views on this. For one thing, in Littlejohn (2014) he argues that environmental luck Gettier cases do not pose a problem for the $\mathrm{R} \rightarrow \mathrm{K}$ thesis. Moreover, he explicitly endorses $\mathrm{R} \rightarrow \mathrm{K}$ in Littlejohn (2013): "The evidence you have consists of those facts that you have the right to treat as a reason for forming further beliefs. Like Hyman (2006) and Williamson (2000), I think that your reasons just consist of what you know" (Littlejohn, 2013, p. 296). Thanks to two reviewers for drawing my attention to this change in Littlejohn's views. 
evidence in favour of the claim that she has coffee but she stubbornly sticks to her belief that she is out of coffee, it does not seem false to conclude that Audrey's reason for going to the store is that she is out of coffee. Littlejohn assumes that if Audrey is out of coffee and she stubbornly sticks to this belief despite the important counter-evidence, then Audrey does not know that she is out of coffee. However, the argument goes, if she does not know that she is out of coffee, then $\mathrm{R} \rightarrow \mathrm{K}$ predicts something that is counter-intuitive, namely, that that she is out of coffee cannot be her reason for going to the store. ${ }^{24}$

My main worry with Littlejohn's argument is that his case seems to be underdescribed in one very relevant aspect. Namely, it is not entirely clear why we should think that Audrey does not know that she is out of coffee. For all we know, Audrey is out of coffee and Audrey sticks to the belief that she is out of coffee, despite the misleading evidence that suggests otherwise. We have not been told the whole story. In particular, we do not know how Audrey acquired her initial belief that she is out of coffee. This detail seems to be crucial, though. Was it formed out of a mere hunch or wishful thinking? Was it formed on the basis of a reliable beliefformation method? Littlejohn does not specify. However, given the set-up of the case, it seems to be intended to be a case of a defeat. Defeat cases are cases where one loses initial knowledge upon receiving a defeater. Presumably, it is a case where the subject had knowledge initially and her belief was acquired on the basis of a good method. Note that if Littlejohn's case is one in which a subject has acquired her belief on the basis of a bad method (e.g., wishful thinking), then it is not clear why should we think that it is intuitive that the fact that Audrey is out of coffee is her reason for going to the store. If a subject believes that $p$ on the mere basis of wishful thinking, it does not seem appropriate to judge that that $p$ is her reason for F-ing. It seems that Littlejohn's argument has to presuppose that Audrey initially had knowledge and then lost it due to receiving misleading evidence. Without this defeat assumption his argument does not seem to get off the ground. The defeat view has a number of proponents within contemporary epistemology. However, it has recently received a number of compelling criticisms. Indeed, the issue (e.g., the possibility of the defeat of knowledge in the presence of new misleading evidence) is controversial (cf. Lasonen-Aarnio, 2010; Baker-Hytch and Benton, 2015). Given the controversy, and given that the possibility of defeat is essential for Littlejohn's counter-argument, it is not clear that we should endorse Littlejohn's line of argument. In the remainder of this section let me present a line of thought that is based on a recent anti-defeat view and that may undermine Littlejohn's considerations.

Recently Maria Lasonen-Aarnio (2010) has defended the view that, contrary to what proponents of defeat have suggested, it is possible for one to maintain 
knowledge that $p$ in a case where one receives misleading evidence that speaks against $p$. In particular, Lasonen-Aarnio considers cases where a subject sticks to her belief that $p$ despite receiving misleading evidence and does not lose or change her initial evidence/basis for her belief after receiving misleading evidence (the belief is still formed on the basis of the initial belief-forming method). Lasonen-Aarnio imagines a case where a subject, Suzy, at a time $t 1$ forms a belief that an object is red on the basis of perception. Suzy comes to know that the object is red; Suzy's perceptual abilities are normal, as is the lighting in the room where Suzy forms her belief. Later, at a time $\mathrm{t} 2$, "a highly reliable and trustworthy authority tells her that the object is illuminated by peculiar red lighting, lighting that would make objects of any colour look red" (Lasonen-Aarnio, 2010, p. 1). Lasonen-Aarnio acknowledges that cases of this sort constitute a challenge for (typical) externalist theories of knowledge (as, for example, for safety approaches), since externalist views predict, counter-intuitively, that if Suzy sticks to her belief that the object is red, she continues to know that the object is red even after receiving the testimony (the basis of Suzy's belief has not changed). Lasonen-Aarnio suggests that our intuitive judgement that there is something wrong with Suzy's belief does not warrant the conclusion that Suzy loses her knowledge that the object is red after receiving the testimony. According to Lasonen-Aarnio, externalists can propose an alternative and principled explanation (e.g., an error theory) of our intuitions in cases like Suzy's. Namely, given Suzy's goal of knowing things and avoiding false beliefs, Suzy's belief (after the testimony) manifests a bad disposition. According to Lasonen-Aarnio, it is possible for one to have unreasonable knowledge, in the sense that one could still maintain knowledge that $p$ even in the light of a lot of misleading evidence. ${ }^{25}$ If one thinks that safety is a necessary condition for knowledge, then if one knows something and, hence, has a safe belief, and, furthermore, sticks to that belief, even in face of misleading evidence, then one still knows. ${ }^{26}$ It seems that Suzy's case is exactly like this: she maintains knowledge, but is in a sense unreasonable given her overall epistemic goals.

Nothing in Littlejohn's example shows that we are not dealing with another case of unreasonable knowledge. On the contrary, it seems that Littlejohn's case fits perfectly what Lasonen-Aarnio calls unreasonable knowledge. Audrey seems to manifest the relevant properties of unreasonable knowledge, as described by

25 The term "unreasonable knowledge" may be a bit confusing, however. The thought here is that there are cases where a subject may know that $p$, but yet manifest an epistemically bad disposition - one may know that $p$ yet at the same time be unreasonable in not revising one's belief that $p$, since following such a policy (e.g., not revising) will result in failing to attain one's goal of knowledge and avoidance of false beliefs in a wide range of cases.

26 The suggestion here is that safety is a necessary condition of knowledge. 
Lasonen-Aarnio. We have no reason for doubting that Audrey's goal is to achieve knowledge and avoid error. As I noticed above, we have no reason for assuming that Audrey's belief was produced on the basis of an unreliable method. In fact, we have some reason for thinking that Audrey's belief was produced on the basis of a reliable method - only such a case could be suitable for Littlejohn's argumentative strategy. In short, it seems reasonable to suppose that Audrey knew that she was out of coffee before considering misleading evidence. Now, it also seems reasonable to think that Audrey has not revised the basis of her belief that she is out of coffee after receiving the misleading evidence. This interpretation of the case is supported by the fact that Littlejohn states that Audrey completely ignored the misleading evidence. Presumably, Audrey maintained her initial belief and the basis of her belief did not change after receiving the misleading evidence. If the initial belief-forming method was reliable (and we have no reason to doubt that it was), then externalist views of knowledge predict that Audrey continued to know even after receiving the misleading evidence. Now, the intuition that there is something bad in Audrey's sticking with the belief that she is out of coffee after discovering misleading evidence can be explained (or so it seems), given Lasonen-Aarnio's general bad disposition approach. Audrey manifested a bad epistemic disposition on this occasion. The disposition is bad because it will result in failing to attain Audrey's goal of achieving knowledge and avoiding false beliefs in a wide range of cases. In light of these considerations we may think that the inference from (IC) to (CLAIM), and hence Littlejohn's objection against Unger, can be rebutted.

\section{Conclusion}

In this article I have examined some often neglected yet crucial considerations for the debate about the condition of having evidence (reasons for belief). These considerations appealed to ordinary language use and common-sense judgements. They suggested that the way we ordinarily speak and intuitively judge cases supports the claim that one's reasons for believing can only be known propositions.

These considerations change the dialectical situation of contemporary debates in epistemology. A prominent contemporary view about evidence holds that one's evidence supervenes on (some of) one's non-factive mental states. In short, one's evidence consists in how things appear from one's own internal perspective (we have labelled this view the phenomenal conception of evidence). A received view in contemporary epistemology is that the phenomenal conception of evidence is supported by the way we ordinarily talk and how we intuitively judge putative and real-life cases. If the considerations from ordinary language use and 
common-sense judgements presented in this article are right, then we should be reluctant to accept the received view.

\section{Acknowledgements}

Many thanks to Julien Dutant, Santiago Echeverri, Pascal Engel, Davide Fassio, Robin McKenna, Timothy Williamson and two anonymous referees for this journal for helpful comments on earlier versions of this article. The research work that led to this article was supported by the Swiss National Science Foundation grant number 161761 .

\section{References}

Arnold, A. (2013) "Some Evidence is False." Australasian Journal of Philosophy 91(1): $165-172$.

AudI, R. (2001) “An Internalist Theory of Normative Grounds." Philosophical Topics 29(1/2): 19-46.

Baker-Hytch, M. and Benton, M. (2015) “Defeatism Defeated." Philosophical Perspectives 29(1): 40-66.

BonJour, L. (1999) "Foundationalism and the External World." Philosophical Perspectives 13(s13): 229-249.

Brown, J. (2008) "Knowledge and Practical Reason." Philosophy Compass 3(6): 1135-1152.

BRUECKNER, A. (2005) "Knowledge, Evidence, and Skepticism According to Williamson." Philosophy and Phenomenological Research 70(2): 436-443.

Colaco, D., Buckwalter, W., Stich, S. and Machery, E. (2014) "Epistemic Intuitions in Fake-Barn Thought Experiments." Episteme 11(2): 199-212.

Comesaña, J., and Kantin, H. (2010) "Is Evidence Knowledge?" Philosophy and Phenomenological Research 80(2): 447-454.

Conee, E. and Feldman, R. (2004) Evidentialism, Vol. 48. Oxford: Oxford University Press.

Conee, E. and Feldman, R. (2008) "Evidence.” In Q. Smith (ed.), Epistemology: New Essays, pp. 83-104. Oxford: Oxford University Press.

Conee, E. and Feldman, R. (2011) "Replies." In T. Dougherty (ed.), Evidentialism and its Discontents. Oxford University Press.

Dancy, J. (2004) “Two Ways of Explaining Actions." Royal Institute of Philosophy Supplement 55: 25-42.

DodD, D. (2007) “Why Williamson Should Be a Sceptic." Philosophical Quarterly 57(229): 635-649.

Dougherty, T. (2011) Evidentialism and its Discontents. Oxford: Oxford University Press.

Dougherty, T. and Rysiew, P. (2013) “What Is Knowledge-first Epistemology?" In M. Steup and J. Turri (eds), Contemporary Debates in Epistemology, pp. 10-16. Oxford: Blackwell.

Dunn, J. (2014) “Inferential Evidence.” American Philosophical Quarterly 51(3): 203-213.

Fantl, J. and McGrath, M. (2009) Knowledge in an Uncertain World. Oxford: Oxford University Press. 
Gendler, T. S. and Hawthorne, J. (2005) "The Real Guide to Fake Barns: a Catalogue of Gifts for Your Epistemic Enemies.” Philosophical Studies 124(3): 331-352.

Goldman, A. (1976) "Discrimination and Perceptual Knowledge." Journal of Philosophy 73 (November): 771-791.

Goldman, A. (2009) "Williamson on Knowledge and Evidence." In P. Greenough, D. Pritchard, and T. Williamson (eds), Williamson on Knowledge, pp. 73-91. Oxford: Oxford University Press.

Harman, G. (2002) "Reflections on Knowledge and Its Limits." Philosophical Review 111(3): 417-428.

Hawthorne, J. (2005) "Knowledge and Evidence." Philosophy and Phenomenological Research 70(2): 452-458.

Hornsby, J. (2007) "Knowledge, Belief, and Reasons for Acting.” In C. Penco, M. Beaney and M. Vignolo (eds), Explaining the Mental Naturalist and Non-Naturalist Approaches to Mental Acts and Processes, pp. 88-105. Newcastle: Cambridge Scholars Publishing.

Hornsby, J. (2008) "A Disjunctive Conception of Acting for Reasons." In A. Haddock and F. MacPherson (eds), Disjunctivism: Perception, Action, Knowledge, pp. 244-261. Oxford: Oxford University Press.

Hughes, N. (2014) “Consistency and Evidence.” Philosophical Studies 169(2): 333-338.

Hyman, J. (1999) "How Knowledge Works." Philosophical Quarterly 50(197): 433-451.

Hyman, J. (2001) "Knowledge and Self-Knowledge.” In S. Schroeder (ed.), Wittgenstein and Contemporary Philosophy of Mind, pp. 171-193. Basingstoke: Palgrave.

Hyman, J. (2006) “Knowledge and Evidence.” Mind 115(460): 891-916.

Hyman, J. (2015). Action, Knowledge, and Will. Oxford: Oxford University Press.

IchiKawa, J. J. (2013) "Basic Knowledge and Contextualist ' $\mathrm{E}=\mathrm{K}$ "' Thought: A Journal of Philosophy 2(4): 282-292.

JACKsON, A. (2012) “Two Ways to Put Knowledge First." Australasian Journal of Philosophy 90(2): 353-369.

Joyce, J. (2004) "Williamson on Evidence and Knowledge." Philosophical Books 45(4): 296-305.

Kelly, T. (2008) "Evidence: Fundamental Concepts and the Phenomenal Conception." Philosophy Compass 3(5): 933-955.

Kelly, T. (2014) “Evidence.” In E. N. Zalta (ed.), The Stanford Encyclopedia of Philosophy (Fall 2014), http://plato.stanford.edu/archives/fall2014/entries/evidence/.

Lasonen-Aarnio, M. (2010) “Unreasonable Knowledge." Philosophical Perspectives 24(1): $1-21$.

Leite, A. (2013) "But That's Not Evidence; It's Not Even True!” Philosophical Quarterly 63(250): 81-104.

Littlejohn, C. (2011a) "Evidence and Armchair Access.” Synthese 179(3): 479-500.

Littlejohn, C. (2011b) “Evidence and Knowledge.” Erkenntnis 74(2): 241-262.

Littlejohn, C. (2012) Justification and the Truth-Connection. Cambridge: Cambridge University Press.

Littlejohn, C. (2013) “The Russellian Retreat." Proceedings of the Aristotelian Society 113: 293-320.

Littlejohn, C. (2014) "Fake Barns and False Dilemmas.” Episteme 11: 369-389.

Logins, A. (2013) “On Williamson's Account of Propositional Evidence.” Logique et Analyse 223: $347-354$. 
McGlynn, A. (2014) Knowledge First? Basingstoke: Palgrave Macmillan.

Mitova, V. (2015) “Truthy Psychologism about Evidence.” Philosophical Studies 172(4): $1105-1126$.

NetA, R. (2008) "What Evidence Do You Have?" British Journal for the Philosophy of Science 59(1): 89-119.

Pritchard, D. (2008) "Radical Scepticism, Epistemic Luck, and Epistemic Value." Aristotelian Society Supplementary Volume 82(1): 19-41.

Rizzieri, A. (2011) "Evidence Does Not Equal Knowledge.” Philosophical Studies 153(2): 235-242.

SCHIFFER, S. (2009) "Evidence = Knowledge: Williamson's Solution to Skepticism?" In P. Greenough, D. Pritchard, and T. Williamson (eds), Williamson on Knowledge, pp. 183-202. Oxford: Oxford University Press.

Schroeder, M. (2011) "What Does It Take to 'Have' a Reason?" In A. Reisner and A. Steglich-Petersen (eds), Reasons for Belief, pp. 201-22. Cambridge: Cambridge University Press.

Silins, N. (2005) "Deception and Evidence.” Philosophical Perspectives 19(1): 375-404.

Turri, J. (2009) “The Ontology of Epistemic Reasons.” Noûs 43(3): 490-512.

Turri, J., Buckwalter, W. and Blouw, P. (2015) "Knowledge and Luck." Psychonomic Bulletin and Review 22(2): 378-390.

Unger, P. (1975) Ignorance: A Case for Scepticism. Oxford: Oxford University Press.

Unger, P. (1980) "Skepticism and Nihilism." Nô̂s 14(4): 517-545.

Wedgwood, P. (2002) “Internalism Explained.” Philosophy and Phenomenological Research 65(2): 349-369.

Whiтсомв, D. (2008) “Williamson on Justification.” Philosophical Studies 138(2): 161-168.

Williamson, T. (2000) Knowledge and its Limits. Oxford: Oxford University Press. 